\title{
Densidade de plantio na cultura da cenoura no Submédio do Vale do São Francisco
}

\author{
Planting density in carrot growing in the Sub-Middlle São Francisco Valley
}

\author{
G. M. Resende ${ }^{1 *}$; N. D. Costa ${ }^{1}$; J. E. Yuri ${ }^{1}$; J. C. Ferreira ${ }^{1}$; J. H. Mota ${ }^{2 *}$ \\ ${ }^{1}$ Embrapa Semiárido, CEP 56302-970, Petrolina-PE, Brasil \\ ${ }^{1}$ Universidade Federal de Goiás -Regional Jataí, CEP 75801-615 - Jataí, GO, Brasil. \\ *email do autor correspondente: geraldo.milanez@embrapa.br \\ (Recebido em 17 de dezembro de 2015; aceito em 11 de março de 2016)
}

\begin{abstract}
A cenoura é a quarta hortaliça mais consumida no país e uma das mais consumidas no mundo. Com o objetivo de avaliar o desempenho produtivo da cenoura em diferentes espaçamentos de plantio conduziu-se um experimento no período de outubro de 2013 a fevereiro de 2014. Utilizou-se o delineamento de blocos ao acaso em esquema fatorial $2 \times 4$, consistindo em dois espaçamentos entre linhas (20 e $25 \mathrm{~cm})$ e quatro espaçamentos entre plantas $(4,6,8$ e $10 \mathrm{~cm})$ com três repetições e utilizando a cultivar Brasília. A altura das plantas oscilou de 52,1 a $53,3 \mathrm{~cm}$ para os espaçamentos entre linhas e de 51,0 a $53,2 \mathrm{~cm}$ nos espaçamentos entre plantas, não se verificando diferenças significativas. Produtividade comercial de raízes superior foi obtida para o espaçamento de $20 \mathrm{~cm}$ entre linhas $\left(40,6 \mathrm{t} \mathrm{ha}^{-1}\right)$, em comparação ao espaçamento de $25 \mathrm{~cm}$ entre linhas $\left(35,4 \mathrm{t} \mathrm{ha}^{-1}\right)$. $\mathrm{O}$ espaçamento $4 \mathrm{~cm}$ entre plantas linhas apresentou maior rendimento de raízes comerciais $\left(44,5 \mathrm{t} \mathrm{ha}^{-1}\right)$. Maior massa fresca de raízes foi observada nos maiores espaçamentos entre linhas e plantas. À medida que se aumentou a população de plantas houve um acréscimo no percentual de raízes de maior comprimento e redução percentual de raízes mais curtas.
\end{abstract}

Palavras-chave: Daucus carota, rendimento, espaçamentos entre linhas e plantas, massa fresca de raiz.

The carrot is the fourth most consumed vegetable in the country and one of the most consumed worldwide. The objective of this work was to analyze the yield performance of carrot cultivar in different spacings. The experiment was carried out from October 2013 to February 2014, using a randomized block design in a factorial $2 \times 4$, consisting of two spacing between rows $(20$ and $25 \mathrm{~cm}$ ) and four plant spacing within the row $(4,6,8$ and $10 \mathrm{~cm})$ and three replications, using the cultivar Brasilia. The plant height ranged from $52.1 \mathrm{~cm}$ to $53.3 \mathrm{~cm}$ in row spacing and $51.0 \mathrm{~cm}$ to $53.2 \mathrm{~cm}$ for plant spacing and there were no significant differences. Commercial yield higher roots was obtained for the spacing between lines of $20 \mathrm{~cm}^{\left(40.6 \mathrm{t} \mathrm{ha}^{-}\right.}$ $\left.{ }^{1}\right)$ as compared to the spacing between rows $25 \mathrm{~cm}\left(35.4 \mathrm{t} \mathrm{ha}^{-1}\right)$. The spacing between plants $4 \mathrm{~cm}$ lines has a higher yield of commercial roots $\left(44.5 \mathrm{t} \mathrm{ha}^{-1}\right)$. As the to increased plant population, there was an increase in the percentage of greater length and percentage reduction in shorter roots roots.

Keywords: Daucus carota, yield, spacings between rows and plants, fresh mass of root

\section{INTRODUÇÃO}

A cenoura (Daucus carota L.) é a quinta hortaliça cultivada no Brasil em ordem de importância econômica [1]. Entre as hortaliças cujas partes comestíveis são as raízes é a de maior valor econômico, apresentando alto conteúdo de vitamina A, textura macia, paladar agradável [2]. Apresenta ainda elevada capacidade de geração de emprego e renda, em todos os segmentos de sua cadeia produtiva, durante o ano inteiro [3].

A produção nacional em 2012 foi de 780,8 mil toneladas, cultivadas em uma área de 26,5 mil hectares, o que proporcionou produtividade média de $29,5 \mathrm{t} \mathrm{ha}^{-1}$ [4]. A produção mundial foi de 
36,9 milhões de toneladas, cultivadas em área de 1,19 milhões de hectares, o que proporcionou produtividade média de $31,0 \mathrm{t} \mathrm{ha}^{-1}$ [5].

Cultivares de verão, como a Brasília, e aquelas do grupo Kuroda, adaptam-se bem às chuvas e temperaturas elevadas; já as cultivares de inverno, como os do grupo Nantes, produzem melhor sob temperaturas amenas ou frias, entre 16 e $20{ }^{\circ} \mathrm{C}$ [6]. Para as condições do Vale do Submédio do São Francisco, temperaturas amenas ocorrem no período de abril a setembro, enquanto de outubro a março são as mais elevadas. Os meses mais quentes são outubro e novembro, que coincidem com a época em que o sol está culminando na região, e os mais frios são junho e julho, quando o sol está culminando no Trópico de Câncer [7].

As propostas de espaçamento e densidade de plantio, para as culturas em geral, têm procurado atender às necessidades específicas dos tratos culturais e a melhoria da produtividade. Todavia, alterações em espaçamento e densidade induzem uma série de modificações no crescimento e no desenvolvimento das plantas e necessitam de melhores esclarecimentos. No caso específico da densidade de plantio, tem sido verificado em trabalhos que os resultados variam de acordo com os cultivares e também com as regiões produtoras [8].

Para a cultura da cenoura são relatados espaçamentos que variam de 15 a $25 \mathrm{~cm}$, ou ainda até $30 \mathrm{~cm}$ entre linhas, e de 5 a $7 \mathrm{~cm}$ entre plantas $[2,9]$.

$\mathrm{O}$ arranjo das plantas é um fator do ambiente que afeta diretamente a produtividade, número e qualidade de raízes comercializáveis da cenoura $[8,10,11]$. A produtividade comercial de cenoura aumenta à medida que se aumenta a densidade populacional, e está diretamente relacionada ao maior número de plantas [8, 12, 13]. Lopes et al. (2008) [8] e Luz et al. (2008) [13] verificaram que a utilização de densidade de plantas muito elevadas resultam em queda na produtividade, redução no comprimento e diâmetro de raízes devido à competição intraespecífica, promovendo efeito semelhante ao da competição exercida pelas plantas daninhas.

Pelo exposto, o presente trabalho teve como objetivo avaliar o comportamento produtivo da cenoura cv. Brasília, em plantio de verão, em diferentes espaçamentos de plantio, para as condições do Submédio do Vale do São Francisco.

\section{MATERIAL E MÉTODOS}

O experimento foi conduzido no período de outubro de 2013 a fevereiro de 2014, em PetrolinaPE (09 $09^{\prime} \mathrm{S}, 40^{\circ} 22^{\prime} \mathrm{W}, 365,5 \mathrm{~m}$ de altitude). O solo classificado como Argissolo Vermelho Amarelo Eutrófico Plíntico [14], com as seguintes características: $\mathrm{pH}\left(\mathrm{H}_{2} \mathrm{O}\right)=5,8 ; \mathrm{Ca}^{2+}=2,1$ $\mathrm{cmol}_{\mathrm{c}} \mathrm{dm}_{-}{ }^{3} ; \mathrm{Mg}^{2+}=0,7 \mathrm{cmol}_{\mathrm{c}} \mathrm{dm}_{-}{ }^{3} ; \mathrm{K}^{+}=0,28 \mathrm{cmol}_{\mathrm{c}} \mathrm{dm}_{-}{ }^{3} ; \mathrm{Al}^{3}=0,01 \mathrm{cmol}_{\mathrm{c}} \mathrm{dm}^{3}$, P/Mehlich $=5,0$ mg dm${ }^{-3}$ e M.O. $=4,8 \mathrm{~g} \mathrm{~kg}^{-1}$ e físicas: areia $=81 \%$; silte $=11 \%$ e argila $=8 \%$. As ocorrências climáticas durante a execução do trabalho foram de temperatura média de $27,4^{\circ} \mathrm{C}$, com mínima em $22,1^{\circ} \mathrm{C}$ e máxima de $33,9^{\circ} \mathrm{C}$, umidade relativa do ar de $58,0 \%$ e precipitação pluviométrica acumulada no período de $252,8 \mathrm{~mm}$. Durante a excução do experimento verificou-se temperatura média de $27,4^{\circ} \mathrm{C}$, mínima em $22,1^{\circ} \mathrm{C}$ e máxima de $33,9{ }^{\circ} \mathrm{C}$, umidade relativa de $58,0 \%$ e precipitação acumulada no período com $252,8 \mathrm{~mm}$ )

$\mathrm{O}$ delineamento experimental utilizado foi de blocos casualizados, sendo os tratamentos dispostos em esquema fatorial 2 x 4, compreendendo dois espaçamentos entre linhas (20 e $25 \mathrm{~cm}$ ) e quatro espaçamentos entre plantas $(4,6,8$ e $10 \mathrm{~cm})$, com três repetições. Utilizou-se a cultivar Brasília.

O preparo do solo constou de uma aração, gradagem e confecção dos canteiros a $0,25 \mathrm{~m}$ de altura, com 2,0 m de comprimento e 1,20 m de largura. A semeadura foi realizada em 20/10/2013 diretamente no canteiro, sendo considerada como área útil as seis linhas centrais. O desbaste foi realizado aos 25 dias após a semeadura, adequando-se a densidade de plantio aos tratamentos estudados.

A adubação de plantio constou de $40 \mathrm{t} \mathrm{ha}^{-1}$ de esterco caprino, $40 \mathrm{~kg} \mathrm{ha}^{-1}$ de nitrogênio, $400 \mathrm{~kg}$ $\mathrm{ha}^{-1}$ de fósforo e $60 \mathrm{~kg} \mathrm{ha}^{-1}$ de potássio. Foram utilizados ainda em cobertura $40 \mathrm{~kg} \mathrm{ha}^{-1} \mathrm{de}$ nitrogênio e $120 \mathrm{~kg} \mathrm{ha}^{-1}$ de potássio, parcelados aos 20 e 40 dias após a emergência [15].

A cultura foi mantida no limpo por meio de capinas manuais. Utilizou-se irrigação por microaspersão com lâminas em torno de $13 \mathrm{~mm}$, três vezes por semana, baseadas na evaporação 
do tanque classe A. Não foram realizados quaisquer tratos fitossanitários contra pragas ou doenças, se observando um bom desenvolvimento vegetativo.

A colheita foi realizada aos 108 dias após a semeadura quando as folhas apresentavam leve tombamento e amarelecimento, indicativo do ponto de colheita. Foram avaliadas a altura de plantas em $\mathrm{cm}$ (medida do solo até a extremidade das folhas mais altas), produtividade total (peso total das raízes, expressa em $\mathrm{t} \mathrm{ha}^{-1}$ ), produtividade comercial (raízes com mais de $10 \mathrm{~cm}$ de comprimento, livres de rachaduras, bifurcações, danos mecânicos, e expressa em $\mathrm{t}^{\mathrm{a}} \mathrm{a}^{-1}$ ), massa fresca da raiz comercial $\left(\mathrm{g} \mathrm{raiz}^{-1}\right)$ e classificação de raízes comerciais em comprimento: Classe 1 (> de 18 a $26 \mathrm{~cm}$ ) e Classe 2 (>10 a $18 \mathrm{~cm}$ ) [16], em percentagem, sendo os resultados para efeito de análise estatística transformados em arco-seno $\sqrt{P / 100}$ e apresentados as médias originais.

Os dados coletados foram submetidos à análise de variância para cada característica avaliada e seus efeitos avaliados pelo teste de $\mathrm{F}$ a $5 \%$ de probabilidade. As médias para espaçamentos entre linhas foram comparadas pelo teste de $\mathrm{F}$ a $5 \%$ de probabilidade e para espaçamentos entre plantas foram ajustadas a equações de regressão polinomiais adotando-se como critério para escolha do modelo, o efeito significativo pelo teste de $\mathrm{F}$ a $5 \%$ de probabilidade e a magnitude dos coeficientes de determinação, empregando-se o programa SISVAR 5.0 [17].

\section{RESULTADOS E DISCUSSÃO}

Os resultados evidenciaram efeitos significativos independentes para espaçamento entre linhas e entre plantas, assim como foram observadas efeitos de interação, variando em função das diferentes características avaliadas.

A altura das plantas oscilou de 52,1 a 53,3 cm nos espaçamentos entre linhas e de 51,0 a 53,2 $\mathrm{cm}$ para os espaçamentos entre plantas (dentro da linha), não se verificando diferenças significativas dos espaçamentos avaliados. Observaram-se que os maiores espaçamentos proporcionaram maiores alturas de plantas, mesmo este não sendo muito diferenciado em termos de valores numéricos. Resultados similares foram obtidos por Lopes et al. (2008) [8], embora com variações menores de altura de planta $(44,8$ a $47,8 \mathrm{~cm})$. Em geral, altas densidades populacionais resultam em menor altura de planta [18].

Maior produtividade total de raízes $\left(48,9 \mathrm{t} \mathrm{ha}^{-1}\right)$ foi alcançada pelo espaçamento de $20 \mathrm{~cm}$ entre plantas comparativamente ao espaçamento de $25 \mathrm{~cm}\left(43,8 \mathrm{t} \mathrm{ha}^{-1}\right)$, atuando os fatores estudados de forma independente. Para espaçamento entre plantas verificaram-se efeito linear decrescente com o incremento do espaçamento, com melhor desempenho para o espaçamento de $4 \mathrm{~cm}$ entre plantas $\left(55,6 \mathrm{t} \mathrm{ha}^{-1}\right)$, sendo a menor produtividade registrada no maior espaçamento de $10 \mathrm{~cm}$ com $37,1 \mathrm{t} \mathrm{ha}^{-1}$ (Figura 1). Lopes et al. (2008) [8] avaliaram os espaçamentos entre linhas (15 e $20 \mathrm{~cm}$ ) e entre plantas $(4,6$ e $8 \mathrm{~cm})$ e obtiveram maiores produtividades também no espaçamento de $20 \mathrm{x}$ $4 \mathrm{~cm}$, assim como Alves et al. (2010) [11] afirmam ser este o melhor espaçamento para a cultura.

Resultados similares foram verificados para produtividade comercial de raízes. Produtividade superior foi obtida para o espaçamento de $20 \mathrm{~cm}$ entre linhas $\left(40,6 \mathrm{t} \mathrm{ha}^{-1}\right)$, em comparação ao espaçamento de $25 \mathrm{~cm}$ entre linhas $\left(35,4 \mathrm{t} \mathrm{ha}^{-1}\right)$. Com o incremento do espaçamento entre plantas observaram reduções na produtividade destacando-se com maior rendimento de raízes comerciais o espaçamento $4 \mathrm{~cm}$ entre plantas linhas $\left(44,5 \mathrm{t} \mathrm{ha}^{-1}\right)$. No maior espaçamento de $10 \mathrm{~cm}$ entre plantas a redução chegou a $29,2 \%\left(31,5 \mathrm{t} \mathrm{ha}^{-1}\right)$. 


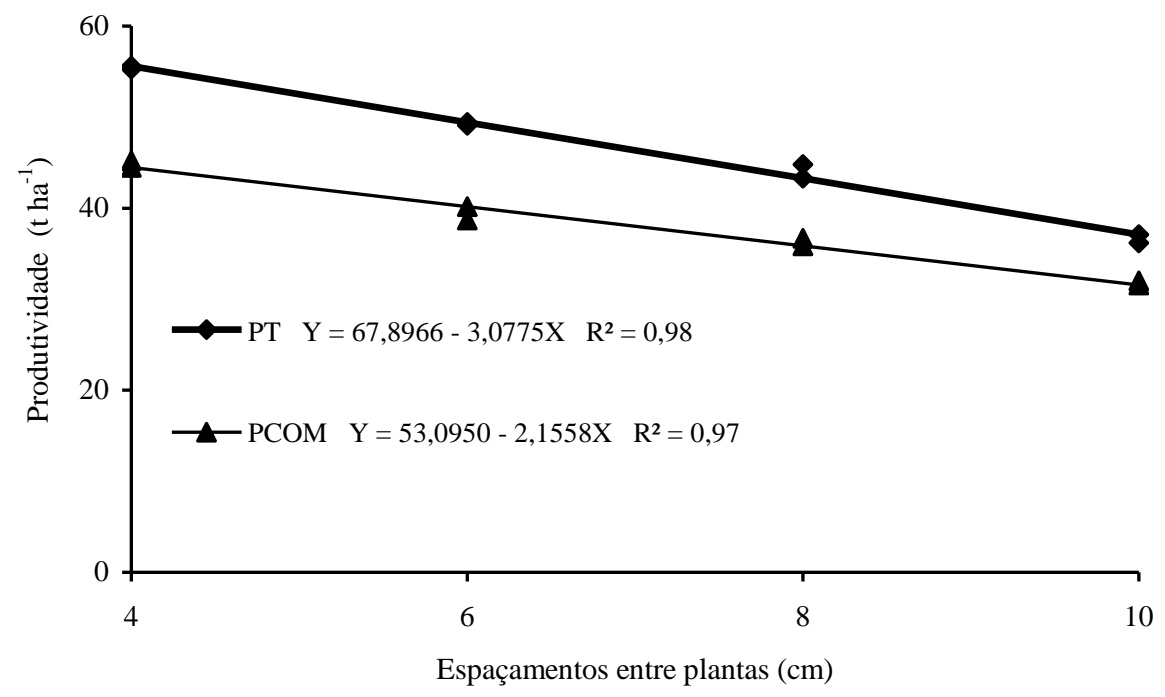

Figura 1. Produtividade total (PT) e comercial (PCOM) de raízes de cenoura de em função de diferentes espaçamentos entre plantas. Petrolina-PE, 2013/2014.

constataram maiores rendimentos para os espaçamentos 20 entre linhas e $4 \mathrm{~cm}$ entre plantas. Maiores espaçamentos entre linhas e plantas proporcionaram menores rendimentos de raízes. Estes resultados sugerem uma adequada população de plantas utilizada, tendo em vista que um número elevado de plantas resulta em menor disponibilidade de radiação fotossintética para as folhas localizadas na parte inferior da planta, acarretando o auto-sombreamento e a redução da taxa fotossintética líquida por planta, com conseqüente redução da produtividade raízes.

Os resultados obtidos, de forma geral são expressivos no que se refere de rendimento, sobretudo levando-se em consideração que a produtividade média nacional da cenoura cultivada é de $31,2 \mathrm{t} \mathrm{ha}^{-1}$ [4] e a mundial de 31,0 $\mathrm{t} \mathrm{ha}^{-1}$ [5]. A média de 42,6 $\mathrm{tha}^{-1}$, obtida pelos espaçamentos entre linhas e entre plantas que proporcionaram maior produtividade $(20 \mathrm{~cm}$ entre linhas e $4 \mathrm{~cm}$ entre plantas), obtiveram-se incrementos da ordem de $36,5 \%$, superior a média nacional. Salientase ainda a boa adaptação da cultivar Brasília, apresentando bom crescimento e desenvolvimento às condições climáticas locais. Segundo Rubatzky et al. (1999) [19], a cenoura pode crescer em temperatura variando de 4 a $40^{\circ} \mathrm{C}$, porém temperaturas entre 10 e $25^{\circ} \mathrm{C}$ propiciam a obtenção de raízes com melhor qualidade. Temperaturas de 18 a $25^{\circ} \mathrm{C}$ são consideradas ideais para $\mathrm{o}$ crescimento da parte aérea. Maiores taxas de crescimento das raízes são obtidas em temperaturas entre 18 a $20^{\circ} \mathrm{C}$. Temperaturas elevadas associadas à alta umidade relativa do ar favorecem o desenvolvimento de doenças fúngicas de folhagem, principalmente a queima-das-folhas [20, 21].

Com relação à massa fresca de raiz (Figura 2), verificaram-se, como era de se esperar, maiores massas de raízes no espaçamento que proporciona maior espaço para o crescimento e desenvolvimento das plantas $(25 \mathrm{~cm})$, totalizando, no entanto, menores populações de plantas por hectare, com consequente perda de produtividade comercial. A massa fresca de raízes apresentou para o espaçamento entre linhas de $25 \mathrm{~cm} 84,1 \mathrm{~g}^{r_{a i z}}{ }^{-1}$ significativamente superior ao espaçamento que $20 \mathrm{~cm}$ que obteve $81,4 \mathrm{~g}$ raiz $^{-1}$. Com efeito independente, o incremento dos espaçamentos entre plantas promoveram aumento linear na massa fresca de raiz, com o espaçamento de $10 \mathrm{~cm}$ atingindo o maior patamar de $99,7 \mathrm{~g} \mathrm{raiz}^{-1}$ verificando-se menor valor no espaçamento de $4 \mathrm{~cm}$ com $65,9 \mathrm{~g}^{\text {raiz }}{ }^{-1}$, o que representa $66 \%$ da maior massa fresca de raiz obtida. Estes resultados são alicerçados por Rajasekaran et al. (2006) [17] e Alves et al. (2010) [11], que relataram que maiores densidades populacionais resultaram em menor massa fresca de raízes. Como também com Silva et al. (2003) [21], que avaliando espaçamentos entre linhas simples e triplas na cultura visando à obtenção de produção de raízes para processamento de minicenouras, observaram que o adensamento proporcionou o aumento de raízes mais finas. No entanto, salientando que até certo limite ocorre a compensação da produtividade pela elevação do número de raízes. 


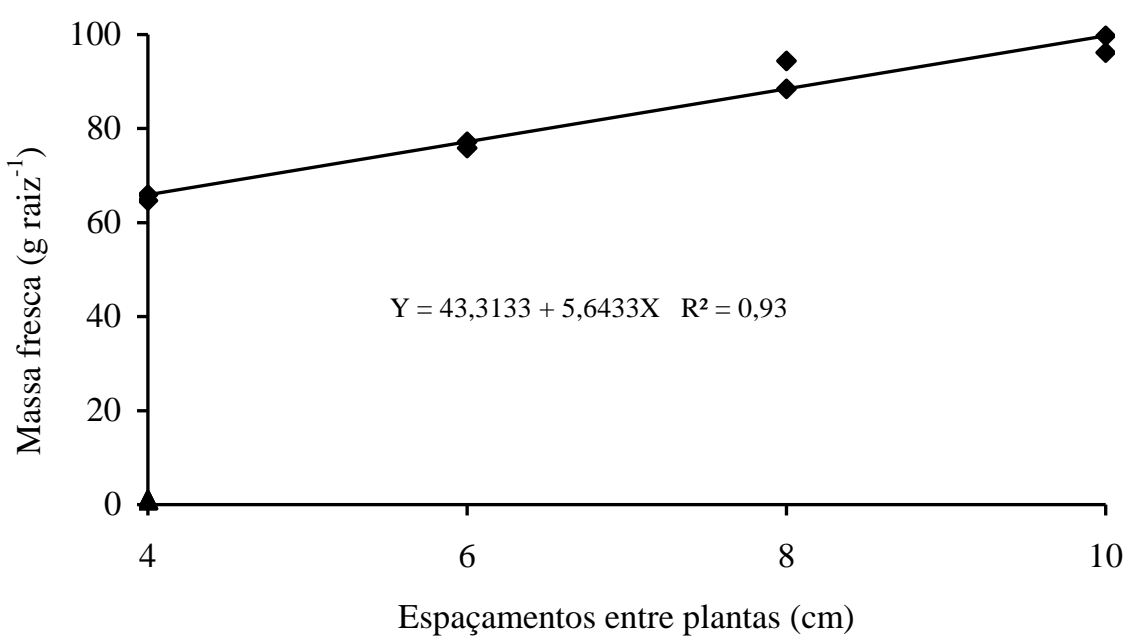

Figura 2. Massa fresca de raízes de cenoura em função de diferentes espaçamentos entre plantas. Petrolina-PE, Embrapa Semiárido, 2013/2014.

Para classificação de raízes comerciais observaram-se efeitos da interação. Constataram-se para classe 1, que são raízes de maior comprimento (raízes > de 18 a $26 \mathrm{~cm}$ ), para os espaçamentos de 20 e $25 \mathrm{~cm}$ entre linhas, redução na produção de raízes comerciais de maior comprimento com o incremento dos espaçamentos entre plantas, onde os espaçamentos de $4 \mathrm{~cm}$ entre plantas apresentaram os melhores desempenhos com 34,4 e 36,3\% (Figura 3).

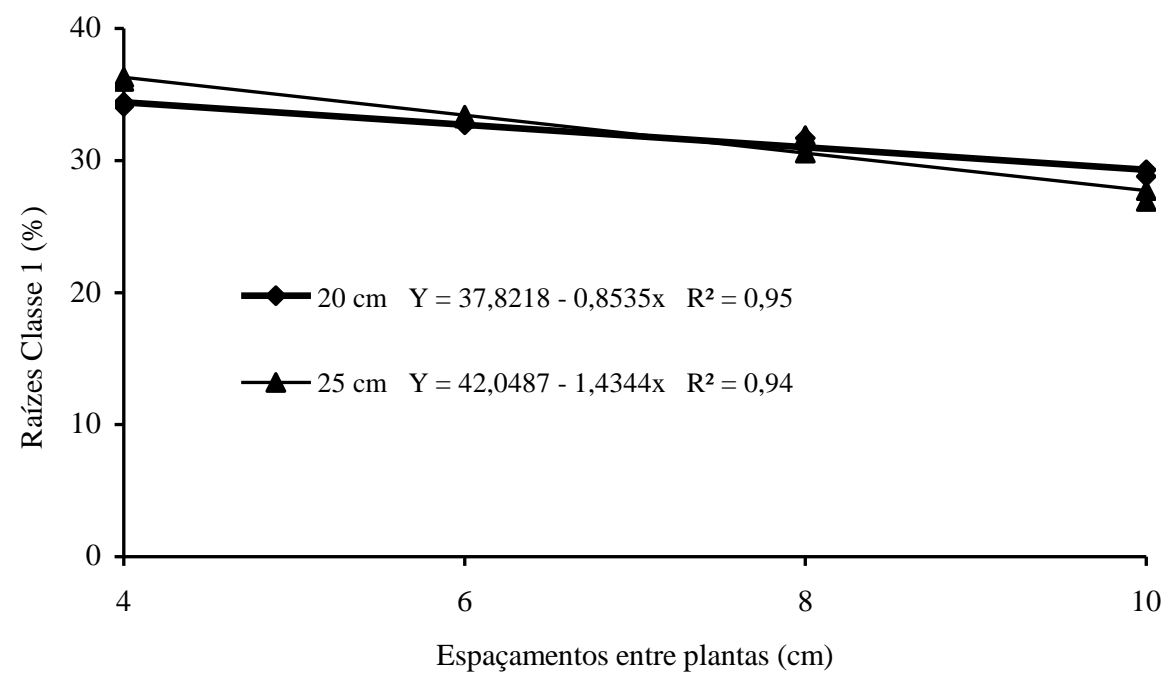

Figura 3. Classificação de raízes cenoura classe 1 (> de 18 a $26 \mathrm{~cm}$ ) em porcentagem de espaçamentos entre linhas em função de diferentes de espaçamentos entre plantas. Petrolina-PE, 2013/2014.

Resultados semelhantes foram verificados para classe 2 (raízes $>10$ a $18 \mathrm{~cm}$ ) que são raízes de menor comprimento, em relação inversa, ou seja, com o incremento dos espaçamentos entre plantas observaram para os espaçamentos entre plantas de 20 e $25 \mathrm{~cm}$ entre linhas um aumento linear na produção de raízes de menor tamanho (Figura 4). O maior espaçamento de $10 \mathrm{~cm}$ apresentou os maiores valores, de $60,7 \%$ para $20 \mathrm{~cm}$ e $62,3 \%$ para $25 \mathrm{~cm}$ entre plantas. Resultados estes, provavelmente, em função da maior ou menor área de exploração pelas plantas, em função da densidade de plantio promover maior competição intra-específica entre plantas de cenoura. $\mathrm{O}$ aumento da densidade, de maneira geral, interferiu na diminuição tanto de raízes com diâmetro superior a $3,0 \mathrm{~cm}$, como do comprimento das raízes $[11,13]$. Para comprimento de raiz, o emprego de espaçamentos menores entre plantas, em geral, propicia a obtenção de raízes maiores [23]. 


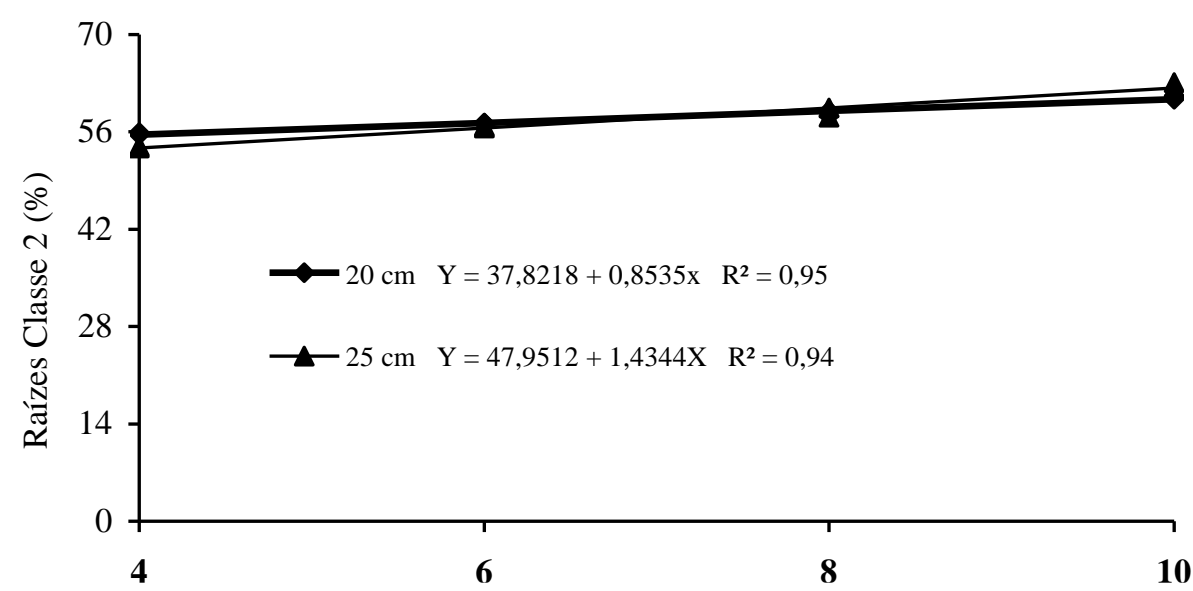

Figura 4. Classificação de raízes cenoura classe 2( > de 10 a $18 \mathrm{~cm}$ ) em porcentagem de espaçamentos entre linhas em função de diferentes de espaçamentos entre plantas. Petrolina-PE, Embrapa Semiárido, 2013/2014.

\section{CONCLUSÃO}

Raízes de maior massa fresca foram obtidas em maiores espaçamentos entre linhas e entre plantas.

O incremento na população de plantas promoveu crescimento percentual de raízes de maior comprimento, e diminuição no percentual de raízes mais curtas.

Em termos de rendimento e de qualidade de raízes os espaçamentos de $20 \mathrm{~cm}$ entre linhas e 4 $\mathrm{cm}$ entre plantas foram os mais adequados para as condições do Submédio do Vale do São Francisco.

\section{REFERÊNCIAS BIBLIOGRÁFICAS}

1. Marouelli WA, Oliveira RA, Silva WLC. Irrigação na cultura da cenoura. Embrapa Hortaliças: Brasília: 14p. 2007. (Embrapa Hortaliças. Circular Técnica, 48).

2. Filgueira FAR. Novo manual de olericultura: agrotecnologia moderna na produção e comercialização de hortaliças. Viçosa: Editora UFV; 3 ed., 2008. 421p.

3. Vilela NJ, Borges IO. Retrospectiva e situação atual da cenoura no Brasil. Brasília: Embrapa Hortaliças; 9p. 2008. (Circular Técnica, 59).

4. Embrapa Hortaliças - CNPH. Situação das Safras de Hortaliças no Brasil - 2000-2012. Disponível em: <http://www.cnph.embrapa.br>. Acesso em 19 agosto 2015.

5. FAO. Agricultural production, primary crops. Disponível em: 〈http://www.fao.org〉. Acesso em: 28 outubro 2015.

6. Souza JL, Resende PO. Manual de horticultura orgânica. Viçosa: Aprenda Fácil; 2003. 564p.

7. Teixeira AHC. Informações agrometeorológicas do Pólo Petrolina, PE/Juazeiro - 1963 a 2009. Petrolina: Embrapa Semiárido; 2010. 21p. (Embrapa Semiárido. Documentos, 233).

8. Lopes WAR, Negreiros MZ, Teófilo TMS, Alves SSV, Martins CM, Nunes GHS, Grangeiro LC. Produtividade de cultivares de cenoura em diferentes densidades de plantio. Revista Ceres. 2008 Set/Out;55(5):482-487.

9. Souza RJ, Machado AQ, Gonçalves LD, Yuri JE, Mota JH, Resende GM. Cultura da cenoura. Lavras: Editora UFLA; 2002. 68p. (Textos Acadêmicos, 22).

10. Bezerra Neto F, Barros Júnior AP, Silva EO, Negreiros MZ, Oliveira EQ, Silveira LM, Câmara MJT, Nunes GHS. Qualidade nutricional de cenoura e alface cultivadas em Mossoró-RN em função da densidade populacional. Horticultura Brasileira. 2006 Out/Dez;24(4):476-480, doi: http://dx.doi.org/10.1590/S0102-05362006000400016

11. Alves SSV, Negreiros MZ, Aroucha EMM, Lopes WAR, Teófilo TMS, Freitas FCL, Nunes GHS. Qualidade de cenouras em diferentes densidades populacionais. Revista Ceres. 2010 Mar/Abr;57(2): 218-223, doi: http://dx.doi.org/10.1590/S0034-737X2010000200013 
12. Barros Júnior AP. Densidades populacionais das culturas componentes no desempenho agroeconômico do consórcio cenoura e alface em bicultivo em faixa. [Tese Mestrado] Mossoró (RN): Escola Superior de Agricultura de Mossoró; 2004. 77p.

13. Luz JMQ, Calábria IP, Vieira JV, Melo B, Santana DG, Silva MAD. Densidade de plantio de cultivares de cenoura para processamento submetidas à adubações química e orgânica. Horticultura Brasileira. 2008, Abr/Jun;26(2): 276-280, doi: http://dx.doi.org/10.1590/S0102-05362008000200030

14. Santos HG, Jacomine PKT, Anjos LHC, Oliveira VA, Oliveira JB, Coelho MR, Lumbrera SJF, Cunha TJF (Eds.). Sistema brasileiro de classificação de solos. 2. ed. Rio de Janeiro: Embrapa Solos; 2006. $306 \mathrm{p}$.

15. Alvarez VHV, Dias LE, Ribeiro AC, Souza R.B. Sugestões de adubação para hortaliças. In: Ribeiro AC, Guimarães PTG, Alvarez VVH (Ed.). Recomendação para o uso de corretivos e fertilizantes em Minas Gerais: 5. Aproximação. Viçosa: Comissão de Fertilidade do Solo do Estado de Minas Gerais; 1999. p.6171-208.

16. CEAGESP. Classificação de cenoura: programa de adesão voluntária, São Paulo: Programa Horti \& Fruti; 1999. 8p. (Folder).

17. Ferreira DF. Sisvar: a computer statistical analysis system. Ciência e Agrotecnologia, 2011 nov/dec;35(6):1039-1042, doi: http://dx.doi.org/10.1590/S1413-70542011000600001

18. Rajasekaran LR, Astatkie T, Caldwell C. Seeding rate and seed spacing modulate root yield and recovery of slicer and dicer carrots differently. Scientia Horticulturae. 2006 Feb;107(4):319-324, doi:10.1016/j.scienta.2005.10.002

19. Rubatzky VE, Quiros CF, Simon PW. Carrots and related vegetable Umbelliferae. Oxon: CABI Publishing; 1999. 304p.

20. Finger FL, Dias DCFS, Puiatti M. Cultura da cenoura. In: Fontes PCR (ed.). Olericultura teoria e prática. Viçosa: Centro de Ciências Agrárias/Departamento de Fitotecnia, Cap. 24., p.371-384, 2005.

21. Vieira JV, Pessoa HBSV. Clima. In: Cenoura. Sistemas de produção, 5, 2008. Embrapa Hortaliças. Disponível em: <http://sistemasdeproducao.cnptia.embrapa.br> Acesso em 13 de novembro de 2015.

22. Silva JBC, Vieira JV, Machado CMM, Lima GB. Rendimento das cultivares de cenoura Alvorada e Nantes Forto cultivadas sob diferentes espaçamentos. Horticultura Brasileira. 2003 Jul;21(2):1-5 (Suplemento 2).

23. Lana MM, Vieira JV. Fisiologia e manuseio pós-colheita de cenoura. Brasília: Embrapa Hortaliças; 2000. 16p. (Circular Técnica, 21). 